\title{
Proper names used as modifiers: A comprehensive functional analysis
}

DOI:

$10.1017 / \mathrm{S} 1360674316000514$

\section{Document Version}

Accepted author manuscript

Link to publication record in Manchester Research Explorer

\section{Citation for published version (APA):}

Breban, T. (2018). Proper names used as modifiers: A comprehensive functional analysis. English Language and Linguistics, 22(3), 381-401. https://doi.org/10.1017/S1360674316000514

\section{Published in:}

English Language and Linguistics

\section{Citing this paper}

Please note that where the full-text provided on Manchester Research Explorer is the Author Accepted Manuscript or Proof version this may differ from the final Published version. If citing, it is advised that you check and use the publisher's definitive version.

\section{General rights}

Copyright and moral rights for the publications made accessible in the Research Explorer are retained by the authors and/or other copyright owners and it is a condition of accessing publications that users recognise and abide by the legal requirements associated with these rights.

\section{Takedown policy}

If you believe that this document breaches copyright please refer to the University of Manchester's Takedown Procedures [http://man.ac.uk/04Y6Bo] or contact uml.scholarlycommunications@manchester.ac.uk providing relevant details, so we can investigate your claim.

\section{OPEN ACCESS}




\section{Proper names used as modifiers: A comprehensive functional analysis ${ }^{1}$}

TINE BREBAN

The University of Manchester

\footnotetext{
${ }^{1}$ I'm very grateful to the two anonymous reviewers for their constructive input, which helped flesh out and sharpen up the argumentation. I would also like to thank my colleagues Julia Kolkmann and John Payne for our valuable discussion of the semantic/pramatics of proper name modifiers. I am further indebted to the audiences at ICAME26, IPRA14, the KULeuven FunC colloquium and especially at the Workshop on Proper Names and Morphosyntax organized at the Freie Universität Berlin in November 2015. Finally, I'd like to thank Bernd Kortmann for being a helpful and patient editor.
} 


\section{ABSTRACT}

My central concern is the special use of proper names in the English noun phrase first discussed by Rosenbach (2006; 2007; 2010, Koptjevskaja-Tamm \& Rosenbach 2005): proper names which are used as modifiers with an identifying function, e.g. the Bush administration ('Which administration does the noun phrase refer to? The one headed by Bush'). On the basis of a corpus study, I argue that existing analyses of Rosenbach (2007) and Schlücker (2013) fail to account for all cases, and also fail to capture the seemingly contradictory syntactic and functional properties of these proper names in a unified way. My alternative analysis is framed within Halliday's (1994) functional model of the English noun phrase, but radically thinks beyond the typical association of functions with word classes (see also Rijkhoff 2009). My proposal is that the majority of these proper names can be analysed as Epithets, a function typically associated with adjectival modifiers such as the red car. A smaller set, proper name modifiers such as a Kerry supporter, are analysed as complements (Payne \& Huddleston 2002). I end by discussing the implications of this dual analysis for another open question, whether proper name modifiers are morphosyntactically phrasal modifiers or part of compounds. 


\section{INTRODUCTION}

This paper deals with the use of proper names (Payne \& Huddleston 2002: 515-9) as modifiers in a noun phrase, e.g. the Obama administration, a Yorkshire terrier, a Cold War hangover. ${ }^{2}$ In their most typical use, proper names constitute a complete noun phrase in their own right, e.g. Obama signed the deal (Payne \& Huddleston 2002: 517), and their function is to denote a referent. This paper is concerned with the less typical use of proper names as modifier. It seeks to answer the question which function(s) proper names have when used in this way.

This question is framed within linguistic theories that analyse the language system in terms of its communicative function (e.g. Dik's Functional Grammar and its successor Functional-Discourse Grammar, Halliday's Systemic Functional Grammar). These theories hold that every element in the language system has a function, and the hierarchical structure of elements in the system corresponds to a functional hierarchy in which lower-level elements have subfunctions which contribute to the overall functions of higher-level structures. For example, in the noun phrase, functions of modifiers, such as qualification and classification, contribute to the general function of the noun phrase, that is, to the denotation of the referent. Functional analyses take the function of an

\footnotetext{
2 Payne \& Huddleston (2002: 515-9) reserve the term proper nouns to single nouns that function as head of a proper name. Proper names are defined as 'expressions which have been conventionally adopted as name of a particular entity’ (Payne \& Huddleston 2002: 515), e.g. Kim, Queen Victoria, The United States of America. When used as modifiers in the noun phrase, proper names such as The Beatles, lose the definite article, e.g. a Beatles album.
} 
element rather than its form to be a primitive. This entails that functions are not strictly bound to one word class or type of phrase, e.g. the classification function can be fulfilled by adjectives ( (heological college), nouns (a law school), multi-word groups (red-brick universities), adverbs (an away game), etc. Functional models do not assume a one-toone relation between an element and a function; they recognize that a single element can have different functions in different cases of actual usage, e.g. the adjective red has a qualifying function in I'm wearing a red T-shirt, but a classifying function in I prefer red grapes. The goal of this paper is to discuss the functional contributions made by proper names as modifiers in the English noun phrase and to explore whether they can be incorporated in existing functional models of the English noun phrase.

Recent corpus-based discussions have shown that the use of proper nouns and nouns in general as modifiers in the English noun phrase is a relatively recent phenomenon. According to Biber \& Gray (2011: 231-2), the use of nominal premodifiers is 'generally rare up until the twentieth century', but undergoes a marked increase in frequency in written registers (newspaper and academic writing in particular) from then on, and continues to increase up until the present day. Rosenbach (2007: 162-3, 165-6) finds an increase in proper noun modifiers as well as noun modifiers overall from 1650-1999 in the British English news texts. Existing models of the English noun phrase, including Keizer's (2007) book on noun phrases with multiple nouns/nominals, do not separately discuss this new use of proper names as modifiers. One point of accepted knowledge is that proper names can be used as modifiers to designate a subtype of the general type of entity denoted by the head noun in English: for example, a Yorkshire terrier is a subtype of terrier. Their function is to add a subclassification to the general type assignment made by the head noun. However, as first observed by Rosenbach $(2006 ; 2007 ; 2010$, 
Koptjevskaya-Tamm \& Rosenbach 2005), not all proper name modifiers establish a subtype. Take for example the Obama administration: this is not a subtype of administration, but rather a specific instance of the type administration that is identified by the proper name Obama, i.e. the administration headed by Obama. In the same vein, it can be argued that Cold War in a Cold War hangover identifies an instance of the type hangover, rather than establishing a subtype, Cold War hangovers.

In the wake of these first papers, a similar use of proper names has been studied for other Germanic languages such as Swedish (Koptjevskaja-Tamm 2013) and German (Schlücker 2013). All studies devote central attention to the 'identifying use' of proper names, but do so with different goals and against different linguistic frameworks. Whereas Koptjevskaja-Tamm's aim is largely descriptive, Rosenbach and Schlücker seek to give a theoretical analysis of identifying proper names that explains their syntactic features and their identifying function. ${ }^{3}$ However, although both analyses explain some features of the identifying use of proper names, neither of them can explain them all in a unified analysis for English.

In addition, the authors identify special cases of proper name modifiers which are not appropriately explained in either of the analyses. Koptjevskaja-Tamm (2013) discusses a special use in which proper names are not used to identifying an instance but to 'typify'

\footnotetext{
${ }^{3}$ Rosenbach (2007) talks about syntactic and semantic features, but the semantic features she discusses are in fact functions, and will be referred to as such in this paper for consistency. The distinction between semantics and function is difficult to establish, and especially when semantics is understood as 'meaning in context' very difficult to draw and perhaps even irrelevant. In the same spirit, I thank the anonymous reviewers for pointing me in the direction of studies of related phenomena in a semantics tradition, which contributed to the development of the functional argument presented here.
} 
it, as e.g. in a Mona Lisa smile or a John Major answer, where the proper name characterizes the smile as enigmatic like that of the Mona Lisa, or the answer as being in the style of John Major's (see also Koptjevskaja-Tamm \& Rosenbach 2005, Rosenbach 2007). It is unclear in the existing analyses how this use of proper names relates to the identifying and the classifying uses and how it should be analysed theoretically. Schlücker (2013) mentions examples such as Sarkozy supporter, Brandt successor, in which the proper name is a complement of the (deverbal) head noun, and not an independent modifier as problematic for the analysis. ${ }^{4}$

A final open question pertains to the morphosyntactic status of the proper name modifiers. Schlücker (2013) and Koptjevskaja-Tamm (2013) state that in German and Swedish proper name modifiers are unambiguously part of proper name-noun compounds. English notoriously lacks water-tight criteria for distinguishing between phrases and compounds. I will argue that the functional and morphosyntactic analyses are interlinked, and that a successful analysis should be plausible on both accounts.

The set-up of this paper is to discuss Rosenbach's and Schlücker's analyses and identify where the analyses do not make correct predictions about the (morpho-)syntactic features and function of the identifying use of proper name modifiers, as well as identify which cases are not covered. The claims are based on the descriptive observations in the papers by Rosenbach, Schlücker and Koptjevskaja-Tamm as well as on a new corpus study that I conducted using a large data sample from the Collins WordbanksOnline corpus. I will then proceed to propose an alternative analysis, which explains the

\footnotetext{
${ }^{4}$ See Payne \& Huddleston (2002: 439-43) on the distinction of modifier versus complement in the noun phrase. I use the term modifier more broadly to mean any 'internal dependent' in the terminology of Payne \& Huddleston (2002: 439).
} 
functional contribution and the syntactic features of identifying proper names, as well as of the other uses of proper name modifiers in the English noun phrase. The new functional analysis also entails a principled analysis of the status of proper name modifiers with regard to the phrase versus compound question. The paper is structured as follows. In Section 2, I will present and evaluate the analyses of Rosenbach (2.1 and 2.2) and Schlücker (2.3 and 2.4). I will propose my alternative analysis in Section 3. The Section is divided into a first subsection introducing the new functional analysis (3.1) and a second one commenting on the place of these proper name modifiers in the phrasecompound discussion (3.2). Section 4 concludes the paper and focuses on the wider impact of the new analysis for models of the English noun phrase.

\section{PREVIOUS ANALYSES OF 'IDENTIFYING’ PROPER NAME MODIFIERS}

\subsection{Rosenbach's analysis of identifying proper names}

Rosenbach's (2006; 2007; 2010, Koptjevskaja-Tamm \& Rosenbach 2005) interest in this particular use of proper names in English is directly related to her interest in the overlap between genitive constructions and constructions with a noun as modifier in English. ${ }^{5}$ Prototypical examples of both constructions are John's in the noun phrase John's book and steam in the steam train. In the first noun phrase, the genitive John's identifies the specific instance of the type book that the noun phrase refers to. Rosenbach refers to

\footnotetext{
${ }^{5}$ Rosenbach and Schlücker talk about proper nouns, which are a subtype of proper names (see footnote 1). Their analysis is not affected by this reduction, and can be extended to the whole set of proper names. Some of Schlücker's examples, the New York stage, are in fact proper names.
} 
similar examples as determiner genitives (Rosenbach 2007: 145). In the second noun phrase, steam establishes a subtype of the type denoted by the head noun train. However, as Rosenbach points out, there are examples such as a girls'school, in which we find a genitive, girls', which does not identify an instance of the type school, but rather designates a subtype of it. Girls' hence has the form of a genitive such as John's, but the semantics or function of a noun modifier such as steam. Girls' is a classifying genitive (Rosenbach 2007: 245-6). Rosenbach argues that classifying genitives present a case of gradience in the sense of Aarts (2007) between the prototypical determiner genitive and noun modifier constructions. ${ }^{6}$

In the same vein, Rosenbach proposes proper names used as identifying modifiers, as in the Obama administration, to be another instance of gradience between these two constructions. Semantically, they have the identifying function of a determiner genitive. In many of the examples, this functional equivalence is reflected in the possibility to alternate the proper name modifier construction with a genitive construction, e.g. the Obama administration :: Obama's administration. Syntactically, they behave like noun modifiers, in that they take up the same position in the noun phrase, close to the head noun. As a result, any adjectival modifiers, which indicate a quality of the referent, have to be placed on front of them, as in the famous West End theatre, the on-loan Portsmouth striker. Determiner genitives take up the position in front of such qualitative modifiers, e.g. the West End's famous theatre and Portsmouth's on-loan striker.

\subsection{Problems with Rosenbach's analysis}

\footnotetext{
${ }^{6}$ While Aarts (2007) was only concerned with syntactic gradience, i.e. partial overlap of syntactic features, Rosenbach includes meaning/function in the set of features constructions can share.
} 
The Achilles heel of Rosenbach's proposal is the suggested relation to the determiner genitive. In order to make this analysis of constructional gradience with the determiner genitive work, Rosenbach has to restrict the proper name construction in several ways. Rosenbach first restricts the construction to definite noun phrases, because the determiner genitive is inherently definite. However, as we saw above with the example a Cold War hangover, and as Rosenbach (2007: 150) acknowledges, identifying proper nouns can occur in indefinite noun phrases.

A second restriction pertains to the range of proper noun modifiers. Rosenbach targets her analysis to one subset, proper nouns denoting a person, e.g. Obama or Guggenheim, and excludes proper nouns denoting a place, a company or brand, a club, etc. The reason is that determiner genitives typically refer to a person. Again, this restricts the explanatory scope of the analysis, as these other proper nouns are used in the same way in the noun phrase to identify specific instances, e.g. a West End theatre.

The proposed gradience with the determiner genitive is not only problematic in terms of these restrictions. As Rosenbach (2007: 151-3) notes, the functional equivalence with the determiner genitive as reflected in possible alternation does not work for all the examples, e.g. the Guggenheim museum does not alternate with Guggenheim's museum. The reason for the incomplete functional equivalence is the fact that determiner genitives express a small range of typical semantic relations between the referent of the noun phrase and the referent denoted by the proper noun. For example, Guggenheim's museum can refer to the museum that is owned by Guggenheim, but not to a museum that is called Guggenheim. It is only when the relation belongs to the 'genitive repertoire' that the constructions are equivalent. Together with John Payne and Julia Kolkmann, I performed 
a corpus study looking into the alternation and its limitations using a data sample from the Collins WordbanksOnline corpus (henceforth CWO) (Breban \& al. 2015). ${ }^{7}$ The data set included 179 examples of proper name modifiers which in theory could allow alternation with the genitive: noun phrases with a definite determiner in which the proper name had an identifying function. The set was not restricted based on the denotation of the proper name and included nouns denoting persons, locations, companies, etc. We classified the examples into three types:

Type 1: alternation with the genitive is not possible

\section{(1) $\quad[\ldots]$ U. S. abuses at the Abu Ghraib prison. (CWO)}

Type 2: alternation with the genitive is possible and the relation between proper name and the referent remains the same

(2) Van der Vaart received the ball with his back to the goal, and played it through to the Auxerre defence $[\ldots](\mathrm{CWO})$

Type 3: alternation with the genitive is possible, but the relation between proper name and the referent is not the same (the interpretation of the identifying relation changes)

(3) The Kobe Bryant case came to a screeching halt when the woman who accused the NBA star dropped the criminal case [...]. (CWO)

In example (3), Kobe Bryant is the accused, whereas the preferred interpretation of the possible genitive alternate, Kobe Bryant's case, involves Kobe Bryant as accuser.

\footnotetext{
${ }^{7}$ The data set we used was a subset of the sample used in Section 3 of this paper (see also Breban 2013).
} 
In addition to these types, we also noted that certain relations which are typically associated with the determiner genitive, kinship, e.g. John's sister, and ownership, e.g. John's bike, did not occur in our data set for proper name modifiers. Based on this piece of negative evidence, we added a fourth type.

Type 4: relation not attested for proper name modifiers (no alternation with the proper name modifier $)^{8}$

Breban et al. (2015) makes it very clear that a functional analysis in terms of equivalence with the genitive is highly problematic as the constructions do not overlap (the analysis both under and overgeneralizes), and does not take into account that the two constructions can lead to different interpretations of the identifying relation.

A final problem, which straddles both the restriction and the equivalence issues, is that it is possible to use a proper name modifier in the same noun phrase as a determiner genitive, e.g. (4).

(4) [...] two girls aged 13 and 14 worked at his Port Kembla brothel. (CWO)

It is only possible to have multiple determiner genitives in English in cases such as John's sister's mother, where the first genitive John's modifies the noun sister (Payne \&

\footnotetext{
${ }^{8}$ Note that it is not impossible for the proper name construction to express a possessive relation, as shown in Rosenbach's (2007) example the Weaver car, meaning the car owned by the Weavers. This suggest that the dispreference might be situated on the level of usage, where speakers opt not to use the proper name construction for prototypical genitive relations.
} 
Huddleston 2002: 468). In (5), there is no such nested relation, his and Port Kembla independently modify brothel.

\subsection{Schlücker's analysis of identifying proper name modifiers in German}

The focus of Schlücker (2013) are German noun + noun compounds in which the first noun does not have a classifying function. These include compounds in which the first noun has an identifying function, e.g. Facebook-Chefin Sheryl Sanders 'Facebook boss Sheryl Sanders', Berlusconi-Prozess 'Berlusconi trial' (Schlücker 2013: 462). Schlücker points out that this construction also occurs in English, and as the translations show, corresponds to the proper name use discussed in this paper. There are, however, certain differences between the two languages. A first one is the analysis of the grammatical relation between the two nouns. For German, which has clearly defined grammatical criteria for distinguishing compounds from phrases, the two form a compound (Schlücker 2013: 450-1). For English, the compound-phrase distinction is much more difficult to make and the status is uncertain (see Section 3.2). A second difference pertains to the range of semantic relations that the proper names express in German and English. With reference to the EUROPARL corpus, Schlücker (2013: 464-5) points out that where English uses names denoting locations, e.g. the Brussels landscape, the New York stage, the German translators employ alternative constructions such as adjectives, Brüsseler Landschaft, or prepositional phrases, die Bühne in New York.

Schlücker's analysis makes use of Rijkhoff's functional analysis of the noun phrase (amongst others Rijkhoff 2002; 2008; 2009). Rijkhoff's (cross-linguistic) model is represented in Figure 1. It includes six functional types of modifiers, five of which are 
associated with specific positions relative to the head noun and other modifiers. The sixth type of modifiers, attitudinal modifiers, is not restricted to a specific location in noun phrase structure and therefore not included in Figure 1.

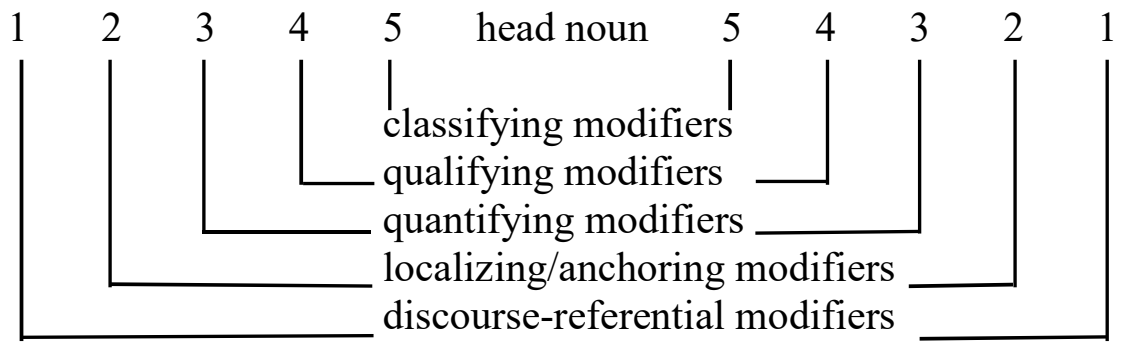

Figure 1

Rijkhoff's layered model of modification functions in the noun phrase

For English, this model maps onto the structure of the noun phrase as follows. Classifying modifiers are elements such as steam in steam train or royal in princess royal, which derive a subtype of the type denoted by the head noun. Qualifying modifiers specify properties of the referent, e.g. the adjective blue in my blue sweater but also a postmodifying description such as a woman with blue eyes. Quantifying modifiers include cardinal numbers and unspecific quantifiers. Discourse-referential modifiers are articles and other determiners, which signal the cognitive status of the referent in terms of identifiability. Localizing/anchoring modifiers provide a way to properly identify the referent by relating it to a location or possessor, and include descriptions of location, e.g. the woman on the bus, time, but also genitives which anchor the referent in terms of a relation to another referent, e.g. John's book.

Schlücker argues that it is this final function that matches the identifying function of proper name modifiers. For her actual definition, Schlücker refers to Zifonun's (2010) 
version of Rijkhoff's model, which downplays the locational element in Rijkhoff's original localizing/anchoring modifiers. Anchoring modifiers are defined by Schlücker as 'modifiers which establish a local, temporal, possessive or other relation between an ... entity in the world and the NP's head noun' and can be 'used to restrict the referential potential of the NP' (Schlücker 2013: 459). Schlücker discusses how this functional definition of the identifying function of proper name modifiers allows for a range of relations to hold between the proper name referent and the noun phrase referent. In accordance with the semantic difference between proper name modifiers in German and English mentioned above, she proposes that German proper name modifiers typically invoke a possessive relation, whereas English ones can invoke possession as well as location (Schlücker 2013: 465). Schlücker (2013: 450, fn. 2) notes that her analysis is transferable to English, even if we were to analyse proper name modifiers in English as phrasal modifiers rather than compounds (see above). In Rijkhoff's model, phrasal modifiers and modifiers in compounds differ only in terms of means of modification, i.e. syntactic versus morphological modification, and can have the same function.

\subsection{Problems with Schlücker's analysis when applied to English}

Schlücker's analysis of German identifying proper name modifiers as anchoring modifiers has a clear instant appeal if extended to English. The open semantic characterization addresses one of the problems identified for Rosenbach's proposal: the fact that proper name modifiers express a wider range of semantic relations than genitives. In addition, the analysis does not restrict the semantic sets of proper name modifiers it 
applies for. The analysis can explain proper name modifiers denoting persons, locations, brands, etc.

However, there are other areas in which Schlücker's analysis is less successful. Firstly, Schlücker takes a categorical stand with regard to the applicability of the analysis to definite and indefinite noun phrases. She argues that the identifying function is per definition not compatible with indefinite reference, because indefinite reference indicates that the referent cannot or does not have to be identified. The presence of an indefinite determiner, which conveys mere class-membership, only allows for proper name modifiers with a classifying interpretation. Even though the first part of her argument concerning the incompatibility seems logical, the second part, the proper name modifier has to have a classifying function, is not a necessary consequence as I will show below. Secondly, the analysis deals much less well with the syntagmatic features of proper name modifiers in English. Rijkhoff's functional classification of modifiers comes with certain predictions about their relative order with regard to the head noun and each other. As shown in Figure 1, anchoring modifiers are associated with the position following discourse-referential modifiers (articles and other determiners that specify the identifiability status of the referent) and preceding quantifying and qualifying modifiers. As already pointed out by Rosenbach (2007), the data for English (and German) show that proper name modifiers do not precede, but in fact follow the latter two types of modifiers.

2.5 What do we expect from a new analysis of English proper name modifiers? 
The discussion of Rosenbach's and Schlücker's analyses allows us to make a check-list of requirements for an alternative analysis. The analysis should accurately explain the function, semantic variety, and syntagmatic features of proper name modifiers irrespective of the type of entity they denote. It should account for proper name modifiers in definite and indefinite noun phrases, and should shed light on the status of proper name modifiers as phrasal modifiers or as part of compounds in English. In addition, in line with the goals set out in the introduction, the analysis should not just focus on the identifying proper names, but seeks to explain all uses of proper name modifiers: it hence includes classifying examples and examples that were marked as 'unexplained', 'typifying' examples such as a Mona Lisa smile, and complement examples such as a Sarkozy supporter.

\section{NEW ANALYSIS}

\subsection{Functional analysis in a Hallidayan framework}

The alternative analysis I am putting forward was tested against a sample of 467 examples of proper name modifiers from CWO (Breban 2013). ${ }^{9}$ It also makes use of an existing

\footnotetext{
${ }^{9}$ The Collins WordbanksOnline corpus is a large corpus of late twentieth century English (http://www.collins.co.uk/page/Wordbanks+Online). The query used was 'element tagged proper noun immediately followed by element tagged common noun'. The rationale behind it was Rosenbach's observation that proper noun modifiers tend to occur close to the head. A query allowing for other modifiers to occur in between proper noun and head would have yielded an unworkable amount of noise. This query had 2710657 hits, from which I took a random sample of 1000 examples. I manually selected
} 
functional model for the description of the English noun phrase, that of Halliday (1994). Halliday proposes a model for the noun phrase that includes six main functions, which are, as in Rijkhoff's model, coupled with a specific position relative to each other, see Figure 2.

Deictic Numerative Epithet Classifier Thing Qualifier

Figure 2

Halliday's model for the English noun phrase

In this model, Thing is the function realized by the head (noun) of the noun phrase. Qualifier is the function associated with any modifiers occurring post-head. The functions in the pre-head area of the noun phrase are Classifier; Epithet, which is Halliday's equivalent of the qualifying function; Numerative, i.e. the expression of quantity or order; and Deictic, conveying the identifiability status of the referent. I will now discuss how the different uses of proper name modifiers can be matched with different functions in this model. The full quantitative break-down of the functional analysis is given in Appendix 1.

\subsubsection{The classifying use of proper name modifiers}

those examples in which the two nouns were part of a single noun phrase in which the second noun functioned as head. I thus excluded examples in which the second noun was a modifier itself, e.g. $a$ Chunnel shuttle loading dock, but allowed examples in which the proper noun was part of a multi-word proper name, e.g. New York city. I also excluded examples of fixed expressions containing the name of a day and the part of a day such as Sunday evening, because they are syntactically idiosyncratic. 
This very brief Section focuses on the traditional classifying use, as in a Yorkshire terrier. In Halliday's model, Yorkshire functions as Classifier. In my data set of 467 examples, 11 were analysed as Classifier (2.36\%).

\subsubsection{The typifying use of proper name modifiers}

A second use that provides a straightforward functional match is the 'typifying' use discussed by Koptjevskaja-Tamm (2013: 273-6). I found only 3 such examples in my sample set $(0.65 \%$ of all examples $)$, which are reproduced here as (5)-(6).

(5) When they weren't reading they played imagination games, Stirling happily undertaking an Alec Guinness multiplicity of roles, [...]. (CWO)

(6) "Wonderful chocolate1" he raved to Madeline. "Where did you get it?" She gave him a Mona Lisa smile. (CWO)

This subset of proper name modifiers is restricted to indefinite noun phrases in my (small) data set, as well as in the examples given by Koptjevskaja-Tamm (2003). In order to assess their function, it is useful to think about possible paraphrases. For Alec Guinness in (5), this could be 'a multiplicity of roles in the style of Alec Guinness' or 'a multiplicity of roles as often displayed by Alec Guinness'. A Mona Lisa smile in (6) is equivalent to 'a smile like that of the Mona Lisa', 'a smile with the same characteristics as that of the Mona Lisa'. Ahmed (2013) argued that is often possible to add the submodifier typical(ly) or type of, as illustrated in typical Flanner impudence 
(CWO). If we consider these paraphrases in terms of communicative functions in the noun phrase, the contribution by the proper name modifiers is a descriptive characterization of the referent. The proper name gives access to a description of a quality or property of the referent, but this property is not named as such, e.g. an enigmatic smile, rather it is given in a more circumspect way, by referring to another referent displaying the property, $a$ Mona Lisa smile. Reasons for using proper name modifiers can be speculated to include the unavailability of a ready-made expression, or the desire of a speaker/writer to be more accurate or more expressive. My claim is that, in terms of function, proper names such as those in (5)-(6) are Epithets.

Supporting evidence is that it is sometimes possible to approximate the property the proper name expresses by a single adjectival Epithet, e.g. a Mona Lisa smile :: an enigmatic smile. Secondly, like adjectival Epithets, these proper name modifiers allow for degree modification, by typical(ly) but also other intensifying adverbials. In (9), for example, it is possible to add the modifier very to the proper name Alec Guinness. Finally, when accompanied by a degree modifier, the proper name modifier displays another characteristic associated with adjectival Epithets, the possibility of a descriptive predicative alternate, e.g. her smile is very Mona Lisa. This Epithet use of proper name modifiers is equally possible with proper names denoting locations, the record is very New York, or companies, a typically Apple design.

\subsubsection{The identifying use of proper name modifiers}

There are 320 examples in which the proper name modifiers have an identifying function in the sense of Rosenbach. They make up $68.5 \%$ of the data set. My pivotal point is that 
the question about the 'identifying' function of the proper name modifiers is not the right one to ask. It is the communicative function of any definite noun phrase to denote an identifiable referent, and all elements in the noun phrase can contribute towards the identification of the referent in such noun phrases. For instance, a father and son are trainspotting and there is one steam train among the set of trains they see. Using the noun phrase the steam train is sufficient to identify that referent and the crucial information for identification is provided by the Classifier steam. The question to ask is not which identifying function does the proper name modifier have, but rather what kind of identifying information does it contribute?

My suggestion is that the contribution by the proper name modifier is not to add a second referent to which the noun phrase referred can be anchored, but instead to add a certain qualifying description. I will illustrate what I mean with an example from my own life, Liesbeth and I are wearing our Berlin boots. Liesbeth, I and the addressee/reader will know that Berlin here means 'that we bought in Berlin whilst I was living there'. Similarly, the bike that Liesbeth's daughter refers to as the Pauline bike is the bike 'that Pauline's parents gave to her when Pauline got too big for it'. These examples show the proper name referent is only a small part of the content that has to be accessed by the addressee/reader. Most of the content, the addressee/reader has to add in him/herself. Koptjevskaja-Tamm's (2013: 276) Masja courses is a similar example in which the meaning (courses taught by Masja) is highly dependent on the context and the shared experience of the speaker/writer and addressee/reader. These proper name modifiers act as a cue for the addressee/reader to reconstruct a (shared) feature of the referent that will allow him/her to identify that referent. Their contribution to the communicative process is a (reconstructable, often complex description of) a feature or property associated with 
the referent, i.e. they function as Epithet. Proper name modifiers are hence similar to qualifying descriptions such as with blue eyes in Rijkhoff's model, but differ in that only part of the description is coded. This analysis also works for the seminal examples discussed by Rosenbach. Obama in the Obama administration conveys the property 'being headed by Obama as president'; Guggenheim in the Guggenheim museum the feature 'being named Guggenheim'. There are two elements to this analysis that require closer argumentation: (1) proper name modifiers imply longer descriptions; (2) these descriptions constitute a property of the referent, i.e. the Epithet analysis.

Firstly, the analysis of proper name modifiers as cues for the reconstruction of a complex description is not new. A similar reconstruction happens when interpreting other types of noun modifiers as illustrated with some examples from Pullum \& Huddleston (2002: 537): a government inquiry 'made by the government' versus the biology syllabus 'dealing with biology' or perhaps 'accompanying the biology course'. One of the reviewers pointed out that a similar process is involved in interpreting the different meanings of ethnic adjectives (e.g. Alexiadou \& Stavrou 2011, Cetnarowska 2013) such as Swiss in Swiss cheese, which can be reconstructed as 'that was made in Switzerland' (provenance meaning) or as 'varieties of cheese which can be produced anywhere and which are in the style of traditional cheeses made in Switzerland' (classifying meaning). Reconstructing additional content is in fact part and parcel of the interpretation of nominal and noun-related modifiers. Noun and by extension proper name modifiers offer a means for the speaker/writer to encode complex descriptions in a more economical way for the speaker/writer (though of course the decoding effort for the addressee/reader is much larger). Rosenbach's (2007) and Biber \& Gray's (2011) believe there might be a genre effect in the historical development of noun modifiers in English. They both suggest it is 
originally associated with written genres, news (Rosenbach) and news and academia (Biber \& Gray). In Breban (2013), I pointed out that a surprisingly large portion of my corpus sample were newspaper headlines, which are known for seeking out compressed formulations. Examples, such as our Berlin boots and Masja courses show that even if the construction originates and is still associated with news and academic genres, it has made its way into informal spoken register as well. The role of genre and the expansion of proper name modifiers is an interesting topic for future study.

The second part of my hypothesis in need of clarification is the suggestion that the complex descriptions denoted by proper name modifiers are Epithets. I argue that the reconstructed descriptions are properties that language users have access to in the real world, in the same way that they have access to properties such as colour, size, provenance, etc. For example, when you ask someone to describe a particular car, they could say 'it is red', 'it is fast', but equally 'it is made by Toyota' or 'it is owned by the Weavers'. The former two properties are traditionally expressed by adjectives, a red car, a fast car, the latter two by proper name modifiers, a Toyota car (CWO), the Weaver car (Rosenbach 2007). It is not unexpected that many relevant properties are more complex than prototypical ones such as colours and sizes, and therefore require different, more complex coding. Alternative, explicit ways to code such complex properties are relative clauses, e.g. 'that we bought whilst I was living in Berlin', 'which is headed by president Obama', or prepositional phrases, e.g. 'as coach of the Dutch national football team' for proper name Holland in example (7). 
(7) [About Ronald Koeman] And he is known to have wanted the Holland job long before it was given to Guus Hiddink after Louis van Gaal quit. (Mirror Online, 14 Oct 2015)

In contrast to the typifying Epithet uses in Section 3.1.2, the proper name modifiers discussed here are never gradable, nor can they be accompanied by scalar modifiers or construed as predicates. This is not problematic: Even though gradability/submodification and predicative alternation are typical features of Epithets, there are other instances in which Epithets do not show these features, e.g. a Sydney-based company (Pullum \& Huddleston 2002: 553), my daily commute. As these examples show, these Epithets are often derived from nouns, adverbs, etc.

\subsubsection{Arguments supporting the Epithet analysis of identifying proper name modifiers}

A first argument supporting the Epithet analysis comes from translation evidence. Schlücker (2013: 464-5) observed that German translations of proper noun modifiers often contained adjectives or prepositional phrases (Section 2.3). My native language Dutch is similar: for English the Brussels landscape, you can have het Brusselse landschap, het landschap in Brussel but not *het Brussel landschap. A possible factor contributing to the usage of proper name modifiers in English is the lack of denominal adjectives for locations such as Brussels and New York (see also Giegerich 2015: 54). In the absence of such adjectives (and productive morphological processes for deriving them on a par with Dutch $-s(e))$, English resorts to using the proper names in the function of Epithet. The absence of denominal adjectives for certain proper names denoting locations 
might in future studies be linked with the fact that proper nouns denoting locations are, historically, among the earliest prenominal noun modifiers (see Rosenbach 2007, Biber \& Gray 2011).

The interaction between proper name modifiers and other Epithets in the same noun phrase lends more support to the Epithet analysis. In two village compounds in the remote Oruzgan province (CWO), the adjectival Epithet remote and the proper name modifier apply independently to the referent: the province is remote and it is called Oruzgan. In an example without context, e.g. the green Weaver car, three interpretations are possible: one option is that the car is green and belongs to the Weavers; when contrastive stress is put on green, the relation changes and green enters in a scopal relation with regard to Weaver ('it is that Weaver car which is green, and not their other, red one for example'); finally, when Weaver is given contrastive stress, the opposite scopal relation becomes the relevant one (it is 'the car that belongs to the Weavers with regard to a set of green cars'). These are similar relations to those between two adjectival Epithets, e.g. the little green dragon versus the 'little green dragon and the little 'green dragon.

One advantage of the Epithet analysis is that it is applicable to proper name modifiers in definite as well as indefinite noun phrases. Epithets are found in both types of noun phrases. The difference in identifying potential is placed with the determination in this analysis. When the determiner is definite, it is possible that the denoted property is the crucial piece of information to identify the referent. The possibility for Epithets to be identifying was noted by Halliday (1994: 184). It is, however, not necessary for the Epithet to describe a property that ensures exclusive identification. In (8), Motherwell does not exclusive identify one player, it identifies a team of players or in this example 
any players that ever belonged to a Motherwell team. The identifiability is instead resolved by the anaphoric relation with the noun phrase Simo Valakari.

(8) Craig Levein, the manager, had been trying to sign his compatriot, Simo Valakari, from Derby County but the FA Barclaycard Premiership side say the former Motherwell player is not for sale. (CWO)

In indefinite noun phrases, e.g. (9), the proper name modifier always describes a property that is not sufficient to identify the referent.

(9) Four family members drowned in a Christmas Day tragedy in Victoria's Grampians. (CWO)

This example illustrates that a Classifier analysis, as suggested a priori by Schlücker (2013) is not appropriate. That analysis assumes a subtype Christmas day tragedies to which speaker and addressee have mental access and from which they can pick one. The Epithet analysis is more intuitive: the referent is a tragedy which happened on Christmas day. Christmas day expresses a property of the referent, rather than deriving a subtype. It can be noted that in certain other examples, e.g. (10), the Classifier analysis does not seem as dissonant.

(10) [...] Ruby Ruggles, is a pretty Suffolk peasant who catches Felix Carbury's eye. (CWO) 
One could envisage language users having a mental subtype Suffolk peasants as opposed to e.g. Norfolk peasants, etc. This might be explained by the fact that subtypes of people based on location are common, whereas subtypes of tragedies based on the time at which they occur are not. The distinction between an Epithet and Classifier analysis is not always clear-cut. While a Christmas day tragedy and a Yorkshire terrier are clear examples of proper names functioning as Epithet and as Classifier respectively, other examples might trigger different judgments from different language users, or maybe be ambiguous for a single language user. The same is true for adjectives. Compare as an example a red car, a red blood cell and a red pepper. In a red car, red is straightforwardly analyzed as Epithet, the referent is a car which is red. A red blood cell unambiguously triggers a Classifier analysis: red blood cells are a subtype of blood cells. But for a red pepper, the decision is harder to make: is the referent a pepper which is red or is there a subtype red pepper in a typology with green and yellow peppers? The decision is based on the individual user's appreciation of established subtypes, and hence can be gradient within the language community and perhaps within one speaker. For 18 examples in my sample set of 467 (3.85\%) it was impossible to unambiguously decide between an Epithet and a Classifier analysis, and they are marked as ambiguous.

So, the Epithet analysis explains the identifying function of these proper name modifiers, without putting any constraints on the denotation of the proper name, or on the semantic relation between proper name referent and noun phrase referent. It accounts for proper name modifiers in definite as well as in indefinite noun phrases. In addition, the Epithet analysis also makes the correct predictions about the relative syntagmatic position of proper name modifiers in English noun phrases. As shown in Figure 2, Epithet follows Numerative and precedes Classifier in Halliday's model. This entails that proper name 
modifiers functioning as Epithet are expected to always follow quantifying modifiers rather than precede them and to always precedes Classifiers rather than be preceded by them. This corresponds to the empirical facts, as illustrated in his first Wembley start (CWO), and in a London dental practice, my Berlin snow boots. ${ }^{10}$ Halliday's model does not make any predictions about the relative ordering of multiple Epithets, so it allows for the order in examples such as the remote Oruzgan province $(\mathrm{CWO})$ or the on-loan Portsmouth striker (CWO). ${ }^{11}$ As such the Epithet analysis ticks off all the items on the check-list in Section 2.5.

\subsubsection{The complement use of proper name modifiers}

In this Section, I turn to examples similar to those that troubled Schlücker (2013: 463467) for German, i.e. examples in which the proper name denotes an internal argument of the deverbal noun, as in Goethe-Vereherung 'Goethe adoration' and SarkozyAnhänger 'Sarkozy supporter', or a complement (Payne \& Huddleston 2002). Payne \& Huddleston (2002: 452-3) treat complements as distinct from modifiers (see footnote 4), and locate Complements in the position immediately to the left of the noun in the English

\footnotetext{
${ }^{10}$ Examples of this kind were not found or excluded from my data set (see footnote 9).

${ }^{11}$ Several analyses have been proposed to explain the order of prenominal modifiers. It is beyond the scope of this article to evaluate all proposals with regard to identifying proper name modifiers. One thing worth noting is that modifiers denoting properties belonging to the semantic category 'provenance' (e.g. location, origin) are positioned closer to the head noun than those denoting size, age, etc. (e.g. Payne \& Huddleston 2002: 453).
} 
noun phrase. The CWO data set contained 115 similar examples (representing $24.63 \%$ of the total data set), two of which are included as (11)-(12).

(11) Ron Reagan, [...], was a vocal Kerry supporter. (CWO)

(12) A Disney spokeswoman said Chartrand was suspended without pay. (CWO)

A John Kerry supporter as a person who supports John Kerry; a Disney spokeswoman is a woman who speaks for Disney. Schlücker argued that examples such as these needed to be excluded from her analysis, as they are not modifiers because 'they do not provide additional information', but 'have an inherent relation to the head noun' (Schlücker 2013: 463). I agree with Schlücker that these examples deserve special consideration, but do not want to simply exclude them.

Complements are not included in Halliday's (1994) model. The only (broadly) Hallidayan study I am familiar with that discusses complements is Feist (2012), who categorizes all modifiers with thematic roles as Classifier. However, Feist's definition of Classifier is semantic in nature and corresponds to what are traditionally referred to as relational or associative adjectives as well as to nouns with similar meanings. If we adhere to the traditional Hallidayan definition of Classifier, i.e. modifiers that denote a subtype of the general type, a Classifier analysis does not seem workable, as it would require us to accept very ad-hoc subtypes: 'John Kerry supporters' and 'Disney spokeswomen'. The most appropriate way to deal with complements in the Hallidayan model seems to consider them to be part of the function Thing, and thus as contributing to the general type description. Applied to example (11), this means that the function Thing would be realized by Kerry supporter. 
This suggestion, to view complement and head as conveying a single function, urges us to revisit the question about morphosyntactic status of proper name modifiers. That is, if we analyze complement and head functionally as one unit does this entail we consider them to morphosyntactically one unit, i.e. to be a compound, rather than a phrase?

\subsection{Phrase versus compound analysis of English proper name + noun combinations}

As we saw in Section 2.3, Schlücker (2013) states that in German proper name modifiers are unambiguously part of noun-noun compounds. As also noted by Schlücker, the phrase-compound distinction is notoriously difficult to make in English, and has been much debated. ${ }^{12}$ A wide range of criteria have been suggested to distinguish between phrases and compounds in English, including semantic ones (phrases are thought to be semantically transparent, while compounds can have a non-transparent meaning), syntactic ones (both elements of phrases can individually enter into relations of coordination and modification, while elements of compounds cannot), productivity (syntactic processes are fully productive, whereas morphological ones are often not), orthography (compounds can be written as a single word, whereas phrases never are), and stress (compounds have primary stress on the first element (fore-stress), while phrases have primary stress on the second element (end-stress)).

Schlücker resolves the problem of the transferability of her analysis by arguing that the phrase-compound status of proper noun modifiers is in fact irrelevant for a functional analysis. Even though I fully agree with the tenet that a radically functional analysis

\footnotetext{
${ }^{12}$ I refer the reader to Giegerich (2015) for a comprehensive discussion of earlier work on this topic.
} 
should abandon reliance on morphosyntax for the assigning of functions, I do believe that the phrase-compound status of proper name modifiers deserves a closer look. A first reason is that the analysis in 3.1 suggests that different uses of proper name modifiers may have different morphosyntactic statuses, complements as part of compounds vs. Classifiers and Epithets as phrasal modifiers. Secondly, the morphosyntactic status of the Classifier and Epithet examples is far from clear. On the one hand, it is possible for Epithets and Classifiers to be followed by Classifiers and, for Epithets, by other Epithets. Given that compounds are traditionally considered not to allow interruption, this supports a phrasal analysis. On the other hand, as one of the reviewers pointed out, many of the proper name examples analysed as Epithets in this paper seem to have fore-stress, e.g. the 'Weaver car, my 'Berlin boots, the 'Holland job, etc., which is usually seen as a reliable indication of compound status. ${ }^{13}$ I seek to clarify this contradicting behaviour. The discussion strongly relies on Giegerich's recent analysis of noun-noun modifiers (2015: Chapter 3, see also Giegerich 2004; 2005).

Giegerich $(2004 ; 2015)$ offers a clear-cut analysis for examples such as a Kerry supporter and a Disney spokeswoman, which are here analyzed as complements. According to Giegerich, elements that are semantically engaged in an Argument-Head relation (i.e. in which the first element functions as a complement) are always compounds

\footnotetext{
${ }^{13}$ A comprehensive analysis of stress patterns is beyond the scope of this paper, and would require a spoken corpus annotated for prosody. The observations in this paper are based on the assessment of stress in individual proper name + noun combinations by a native speaker of British English. As such all discussions, in particular claims about relative frequency, are preliminary.
} 
and always have fore-stress. ${ }^{14}$ Giegerich's proposal about invariable fore-stress appears to match the stress pattern in these examples, a 'Kerry supporter and a 'Disney spokeswoman. The compound analysis also seems to be supported by the syntactic proone test, which Giegerich applies to distinguish between phrases and compounds. Application of the syntactic criterion of pro-one to these two examples does not give grammatical results, *a Kerry supporter and an Obama one and *a Disney spokeswoman and a Pixar one. The compound analysis strengthens the case for analysing these proper name modifiers as part of Thing in Halliday's model.

Proper name modifiers analyzed as Epithets in Section 3.1 present a more complex picture: even though fore-stress appears to be very frequent, there is variation, e.g. the O'bama administration, the 'Holland job, a 'Cambridge student, but also a Suffolk 'peasant, a London 'theatre, the London 'fog. The variation and prevalence of fore-stress can be explained. Giegerich (2015: 50-2) proposes one general exception to the invariable association of phrases with end-stress. He argues that fore-stress is the normal pattern in noun phrases with the definite article when the modifier is restrictive. Giegerich's claim is that the green cars (and any other definite noun phrase) has end-stress in case of the non-restrictive interpretation, the green 'cars, but fore-stress in the restrictive interpretation, the 'green cars. This is the normal stress pattern accompanying a restrictive interpretation in definite noun phrases, and not the result of contrastive or emphatic stress.

The correlation between stress and semantics in definite noun phrases has important consequences for the proper name data. Identifying Epithets, which are found in definite

\footnotetext{
${ }^{14}$ Counterexamples to the fore-stress pattern, such as the Tory 'leader problem (Giegerich 2004: 19-20) are explained away as also allowing an Attribute-Head interpretation ('leader who is also a Tory' or 'leader on a global scale' for world 'leader).
} 
noun phrases, are by definition restrictive, given that they provide the crucial information for the identification of the referent. Following Giegerich's hypothesis, we would expect these proper name + noun combinations to have fore-stress. This is also what seems to be the case. Most of the examples of this kind in this paper appear to have fore-stress. The counterexample the London 'fog is quoted by Giegerich (2015: 60). Interestingly, Giegerich's suggestion is that end-stress can be explained by combinations like London fog having a more attribution (i.e. qualifying)-like semantics. This chimes in naturally with the Epithet analysis proposed in this paper. The difference between London fog and the other examples would hence boil down to restrictiveness, i.e. London does not restrict the reference set (see also Section 3.1.3 in which it is explained that Epithets in definite noun phrases not always provide identifying information, but always refer to a property).

For indefinite noun phrases, Giegerich (2015: 51) argues, fore-stress does not have the same disambiguating role with regard to the restrictive-non-restrictive interpretation. Modifiers in phrases with fore-stress are always restrictive, but those in phrases with endstress allow for both interpretations. Looking at the proper names functioning as Epithet and Classifier in indefinite noun phrases, the impression is that they display more variability in terms of stress than their counterparts in definite noun phrases, e.g. 'Masja courses, a 'Cambridge student and a Suffolk 'peasant, a London 'theatre. Those examples with stress on the proper name do all fit with a restrictive interpretation. By contrast, the larger context for Suffolk peasant in (10), Ruby Ruggles, is a pretty Suffolk peasant who catches Felix Carbury's eye, suggests that Suffolk is non-restrictive. It thus seems probable that the restrictiveness of the proper name modifier is the crucial factor interacting with stress, and a full prosodic study of proper name modifiers should take this association as starting hypothesis. 
The main take-home message of this discussion is that a prevalent pattern of forestress does not preclude a phrasal analysis. In fact, a phrasal analysis is suggested in the literature for examples such as a Cambridge student (see Giegerich 2004: 4-5). Payne \& Huddleston (2002: 448-9) use London colleges as their token example of composite nominals (i.e. phrasal structures). A phrasal analysis also seems to be most suited in the light of productive 'ad hoc' examples such as our Berlin boots. This suggestion does not entail that all Epithet and Classifier examples in the data set are best analysed as phrases. For example, Yorkshire terrier, Guggenheim museum are likely to be accessible as a lexical unit for language users, in a way that Suffolk peasant or Berlin boots are obviously not. Examples such as this are best treated as lexicalizations based on phrasal structures (cf. Giegerich 2004; 2015). Sunday evening and similar 'name of day + time of day' combinations (see also footnote 9) in fact constitute a whole set of lexicalizations based on a more abstract lexicalized pattern, in line with Giegerich's $(2004 ; 2015)$ suggestion for compounds ending Road. My overall suggestion is then that proper name modifiers functioning as complement are part of compounds, whereas proper name modifiers functioning as Epithet or Classifier are phrasal, unless they have lexicalized or are instances of existing abstract lexicalized patterns.

\section{SUMMARY OF THE ARGUMENT AND IMPLICATIONS OF THE NEW ANALYSIS}

The topic of this paper were proper names used as modifiers in the English noun phrase. I confirmed the claim that not all proper name modifiers have a classifying function. However, I argued that the term 'identifying' uses was misleading, as this is not a property of the proper name modifier itself, but one that is derived from the definiteness of the 
noun phrase. The pertinent question is what kinds of information these proper name modifiers contribute to the denotation of the referent. I suggested that the 'identifying' uses in the majority of cases contributed the description of a feature or property of the referent, and therefore realized Halliday's function Epithet, which is traditionally associated with adjectives. Different from adjectival Epithets, proper name modifiers do not code the property itself, but rather act as a prompt to the addressee/reader to reconstruct the full description of the property. The new analysis accounts for proper name modifiers in definite as well as indefinite noun phrases, denoting entities of all kinds of semantic sets (persons, locations, brands, etc.), and places no restrictions on the semantic relation between the referent of the proper name and the referent of the noun phrase. It also explains why proper name modifiers occur in a position following quantifiers and other Epithets. In order to arrive at a full picture of proper name modifiers, I also discussed how any other attested uses of proper name modifiers can be analyzed in the Hallidayan model: classifying proper names function as Classifier and the special uses marked as problematic in the literature, typifying and complement uses, were analysed as Epithet and part of Thing, respectively. Finally, I discussed how this analysis fits in with Giegerich's (2015) recent suggestions about the relation between stress patterns and the phrase-compound distinction. The analysis provides a comprehensive and coherent picture of the functions of proper name modifiers in English noun phrase.

The analysis has immediate theoretical implications for the Hallidayan model of the English noun phrase. I suggested how complements can be included in Halliday's model as part of the realization of the function Thing. This entails that Thing can be realized by simple nouns as well as by compound nouns. In the same vein but more controversially, I suggested that the morphosyntactic realization of the function Epithet should be 
reconsidered to include proper name modifiers in addition to adjectives. Halliday (1994: 185) himself already departs from a one-to-one correspondence between word classes and functions in that adjectives can realize three functions including Epithet and Classifier, and nouns can realize two functions, Classifier and Thing in his model. However, the only function for which he gives multiple realizations is Classifier (adjectives, nouns). The present analysis hence more radically detaches form and function, in a similar way to Rijkhoff (2002; 2009), and exclusively relies on function as the decisive primitive (see also Croft 2000). As such, the way is open for the further extension of the Epithet function to other morphosyntactic realizations. One famous example that immediately springs to mind is Downing's (1977: 818-9) the apple juice seat (see also Schlücker 2013), in which the noun phrase referent was a specific seat in front of which stood a glass of apple juice. Here, a similar analysis as Epithet, where the modifier apple juice instructs the reconstruction of a feature of the referent, captures the modifier's functional contribution. This is food for thought for future analyses of the relation between function and morphosyntax. In the course of argument, I also pointed out where future research into the history and prosody of proper name modifiers can provide further corroboration for the analysis, and vice versa where this analysis makes interesting hypotheses with regard to the historical development of modifiers in the noun phrase and the phrase-compound distinction in English. 
Author's address:

Department of Linguistics and English Language

The University of Manchester

Samuel Alexander Building

Oxford Road

M13 9PL Manchester

United Kingdom

E-mail: tine.breban@manchester.ac.uk 


\section{REFERENCES}

Aarts, Bas. 2007. Syntactic gradience: The nature of grammatical indeterminacy. Oxford: Oxford University Press.

Ahmed, Saphia. 2013. Functions of proper noun modifiers in pre-head position within the noun phrase. Student essay, The University of Manchester.

Alexiadou, Alexiadou \& Melita Stavrou. 2011. Ethnic adjectives as pseudo-adjectives. Studia Linguistica 65, 1-30.

Biber, Douglas \& Bethany Gray. 2011. Grammatical change in the noun phrase: The influence of written language use. English Language and Linguistics 15(2), 22350.

Breban, Tine. 2013. A new analysis of proper noun modifiers in PDE NPs. Presented at ICAME34, 22-5 May 2013, Santiago de Compostela.

Breban, Tine, Julia Kolkmann \& John Payne. 2015. Is the Ghana problem Ghana's problem? Differing interpretations of two English NP constructions. Presented at IPRA14, 26-31 July 2015, Antwerp.

Cetnarowska, Bożena. 2013. Polish and English denominal adjectives: Lexical ambiguity and alternate syntactic configurations. In Anna Bondaruk \& Anna MalickaKleparska (eds.), Ambiguity: Multifaceted structures in syntax, morphology and phonology, 91-109. Lublin: Wydawnictwo Katolickiego Uniwersytetu Lubelskiego.

Collins WordbanksOnline. HarperCollins. http://www.collinslanguage.com/contentsolutions/wordbanks [Accessed January 2013- August 2016] 
Croft, William. 2000. Parts of speech as language universals and as language-particular categories. In Petra M. Vogel \& Bernard Comrie (eds.), Approaches to the typology of word classes, 65-102. Berlin: Mouton.

Downing, Pamela. 1977. On the creation and use of English compound nouns. Language $53,810-42$.

Feist, Jim. 2012. Premodifiers in English: Their structure and significance. Cambridge: Cambridge University Press.

Giegerich, Heinz J. 2004. Compound or phrase? English noun-plus-noun constructions and the stress criterion. English Language and Linguistics 8(1), 1-24.

Giegerich, Heinz J. 2005. Associative adjectives in English and the lexicon-syntax interface. Journal of Linguistics 41(3), 571-91.

Giegerich, Heinz J. 2015. Lexical structures: Compounding and the modules of grammar. Edinburgh: Edinburgh University Press.

Halliday, M.A.K. 1994. An introduction to Functional Grammar, $2^{\text {nd }}$ edn. London: Arnold.

Keizer, Evelien. 2007. The English noun phrase: The nature of linguistic categorization. Cambridge: Cambridge University Press.

Koptjevskaja-Tamm, Maria. 2013. A Mozart sonata and the Palme murder: The structure and uses of proper-name compounds in Swedish. In Kersti Börjars, David Denison \& Alan Scott (eds.), Morphosyntactic categories and the expression of possession, 253-290. Amsterdam/Philadelphia: John Benjamins.

Koptjevskaja-Tamm, Maria \& Anette Rosenbach. 2005. On the fuzziness of nominal determination. MS, University of Stockholm and University of Düsseldorf. 
Payne, John \& Rodney Huddleston. 2002. Nouns and noun phrases. In Rodney Huddleston \& Geoffrey K. Pullum. The Cambridge grammar of the English language, 323-523.Cambridge: Cambridge University Press.

Pullum, Geoffrey K. \& Rodney Huddleston. 2002. Adjectives and adverbs. In Rodney Huddleston \& Geoffrey K. Pullum. The Cambridge grammar of the English language, 525-95. Cambridge: Cambridge University Press.

Rijkhoff, Jan. 2002. The noun phrase, $2^{\text {nd }}$ edn. Oxford: Oxford University Press.

Rijkhoff, Jan. 2008. Descriptive and discourse-referential modifiers in a layered model of the noun phrase. Linguistics 46, 789-829.

Rijkhoff, Jan. 2009. On the co-variation between form and function of adnominal possessive modifiers in Dutch and English. In William B. McGregor (ed.), The expression of possession, 51-106. Berlin: Mouton de Gruyter.

Rosenbach, Anette. 2006. On the track of noun+noun constructions in Modern English. In Christoph Houswitschka, Gabriele Knappe \& Anja Müller (eds.), Anglistentag 2005 Bamberg: Proceedings of the conference of the German association of university teachers of English, 543-57. Trier: Wissenschaftlicher Verlag Trier.

Rosenbach, Anette. 2007. Emerging variation: Determiner genitives and noun modifiers in English. English Language and Linguistics 11(1), 143-89.

Rosenbach, Anette. 2010. How synchronic gradience makes sense in the light of language change (and vice versa). In Elizabeth C. Traugott \& Graeme Trousdale (eds.), Gradience, gradualness and grammaticalization, 149-79. Amsterdam/Philadelphia: John Benjamins.

Schlücker, Barbara. 2013. Non-classifying compounds in German. Folia Linguistica 47(2), 449-80. 
Zifonun, Gisela. 2010. Possessive Attribute im Deutschen. Deutsche Sprache 38, 124 52.

APPENDIX 1

\begin{tabular}{lll}
\hline Epithet & $\mathbf{3 2 3}$ & $\mathbf{6 9 . 1 6 \%}$ \\
\hline Classifier & 11 & $2.36 \%$ \\
\hline Epithet/Classifier & 18 & $3.85 \%$ \\
\hline complement as part of Thing & 115 & $24.63 \%$ \\
\hline Total & 467 & $100 \%$ \\
\hline & Table 1
\end{tabular}

Distribution of the functions of proper name modifiers in the CWO data sample 